Ciência Florestal, Santa Maria, v. 25, n. 2, p. 457-467, abr.-jun., 2015

ISSN 0103-9954

\title{
ESTRATÉGIAS NA SELEÇÃO SIMULTÂNEA DE VÁRIOS CARACTERES NO MELHORAMENTO DO Eucalyptus
}

\section{STRATEGIES IN SIMULTANEOUS MULTIPLE TRAIT SELECTION IN Eucalyptus BREEDING}

\author{
Cristiane Aparecida Fioravante Reis ${ }^{1}$ Flávia Maria Avelar Gonçalves² ${ }^{2}$ Magno Antonio Patto Ramalho ${ }^{3}$ \\ Antônio Marcos Rosado ${ }^{4}$
}

\section{RESUMO}

Este trabalho foi realizado com objetivo de: i) comparar o índice de seleção somatório $Z$ das variáveis padronizadas em relação ao clássico (SMITH, 1936; HAZEL, 1943) e soma de postos (MULAMBA e MOCK, 1978), por meio de caracteres de crescimento e tecnológicos da madeira e ii) verificar a interação progênies $\mathrm{x}$ ambientes na seleção simultânea de vários caracteres, com base no somatório $\mathrm{Z}$ das variáveis padronizadas. Para isto, foi utilizado um teste de progênies de irmãos completos de Eucalyptus urophylla e Eucalyptus grandis avaliado em dois ambientes no município de Ipaba - MG. Aos três anos de idade, foram avaliadas as seguintes características: incremento médio anual de madeira, densidade básica da madeira, rendimento depurado de celulose e álcali efetivo. Houve boa concordância na seleção de progênies pelos índices. Assim, o emprego do somatório $\mathrm{Z}$ das variáveis padronizadas é uma boa opção na seleção simultânea de vários caracteres no setor florestal, pela facilidade de aplicação e, sobretudo, de interpretação dos resultados. O referido índice se mostrou eficiente no estudo da interação genótipos x ambientes.

Palavras-chave: Eucalipto; teste de progênies; índices de seleção; propriedades tecnológicas da madeira.

\begin{abstract}
The aim of this study was i) to compare the results obtained with the $\mathrm{Z}$ index (sum of standardized variables) in relation to the classical (Smith, 1936; HAZEL, 1943) and rank sum indexes (Mulamba and MOCK, 1978) by means of the growth and wood technology traits and ii) to verify the progeny $x$ environment interaction in simultaneous multiple trait selection, based on the $\mathrm{Z}$ index. Thus, we used a full sib progeny test of Eucalyptus urophylla and Eucalyptus grandis evaluated in two locations in the municipality of Ipaba, Minas Gerais state. At three years of age, the following traits were evaluated: average yearly increase of wood, wood density, refined pulp yield and effective alkali. There was good agreement in the progeny selection by the indexes. Thus, use of the $\mathrm{Z}$ index of standardized variables is a good option in simultaneous selection of multiple traits in the forestry sector through its ease of application and, above all, interpretation of results. The mentioned index revealed efficient in the study of the genotypes $\mathrm{x}$ environments interaction. Keywords: Eucalypts; progeny test; selection indexes, technological properties of wood.
\end{abstract}

1 Engenheira Florestal, Dr ${ }^{\mathrm{a}}$., Pesquisadora em Melhoramento Genético de Espécies Florestais, Embrapa Florestas, Rodovia BR-153, Km 4, Caixa Postal 714, CEP 74001-970, Goiânia (GO), Brasil. cristiane.reis@embrapa.com.br

2 Engenheira Agrônoma, Dra ., Professora Adjunta do Departamento de Biologia, Universidade Federal de Lavras, Campus Universitário, Caixa Postal 3037, CEP 37200-000, Lavras (MG), Brasil. avelar@dbi.ufla.br

3 Engenheiro Agrônomo, Dr., Professor Titular do Departamento de Biologia, Universidade Federal de Lavras, Campus Universitário, Caixa Postal 3037, CEP 37200-000, Lavras (MG), Brasil. magnoapr@dbi.ufla.br

4 Engenheiro Florestal, Dr., Coordenador de Silvicultura, Eldorado Brasil Celulose e Papel, Rodovia Marechal Rondon, Km 641, CEP 16901-340, Andradina (SP), Brasil.

Recebido para publicação em 5/07/2010 e aceito em 12/07/2013 


\section{INTRODUÇÃO}

Por algumas décadas, o melhoramento genético do gênero Eucalyptus no Brasil foi direcionado para a produtividade de madeira. O sucesso obtido foi enorme (VENCOVSKY e RAMALHO, 2000; SILVA e BARRICHELLO, 2006). Entretanto, adicionalmente, também os caracteres associados às propriedades tecnológicas da madeira têm recebidomaior atençãorecentemente. Neste contexto, é importante mencionar que o aumento da produtividade, aliado à melhoria das propriedades tecnológicas da madeira, contribuem para a redução de custos operacionais, melhoria do desempenho da matéria-prima no processo industrial, bem como na adequação dessa matériaprima à fabricação de produtos de alta qualidade para diferentes segmentos de mercado (ASSIS e MAFIA, 2007).

Inicialmente a procura foi pela identificação de caracteres que pudessem ser avaliados com precisão no campo e que fossem associados às propriedades tecnológicas da madeira. Assim, o procedimento ideal era aquele que não necessitasse do abate das árvores para a obtenção dos dados. Com o decorrer do tempo e o aprimoramento das técnicas, o emprego da Espectroscopia no Infravermelho Próximo (Near Infrared Spectroscopy - NIR) (PASQUINI, 2003) possibilitou que esses dados fossem obtidos como almejado.

A partir de então, os programas de melhoramento do Eucalyptus passaram a manusear um maior número de variáveis. Nesse caso, existem algumas alternativas que auxiliam na escolha dos melhores indivíduos e/ou progênies, a mais utilizada é o índice de seleção (BERNARDO, 2002; CRUZ e CARNEIRO, 2006). A proposta do primeiro índice foi realizada na década de 30 do século passado por Smith (1936) e Hazel (1943), desde então, inúmeras alternativas foram propostas. Inclusive, algumas delas foram avaliadas no setor florestal (PAULA et al., 2002; MARTINS et al., 2003; MARTINS et al., 2006). Todas essas metodologias apresentam vantagens e desvantagens. Entretanto, o que se deseja é um procedimento que seja de fácil análise e interpretação. A proposta do índice que utiliza o somatório $\mathrm{Z}$ das variáveis padronizadas associado à visualização gráfica se enquadra no almejado (MENDES et al., 2009). No entanto, esse procedimento ainda não foi avaliado no setor florestal.

Deve-se também salientar que trabalhos a respeito da interação genótipos $\mathrm{x}$ ambientes em Eucalyptus são frequentes (MORI et al., 1988; SANTOS et al., 1990; PEREIRA et al., 1997; NUNES et al., 2002, LIMA et al., 2011; REIS et al., 2011). Entretanto, o efeito dessa interação em relação à seleção simultânea para vários caracteres ainda é muito pouco explorado. Do exposto, foi realizado o presente trabalho com os seguintes objetivos: i) comparar os resultados obtidos com o índice de seleção somatório $\mathrm{Z}$ das variáveis padronizadas em relação ao clássico (SMITH, 1936; HAZEL, 1943) e soma de postos (MULAMBA e MOCK, 1978), por meio de caracteres de crescimento e tecnológicos da madeira e ii) verificar a interação progênies $\mathrm{x}$ ambientes via seleção simultânea quando se emprega o somatório $\mathrm{Z}$ das variáveis padronizadas.

\section{MATERIAL E MÉTODO}

O experimento foi composto por um teste de progênies avaliado em dois ambientes da Empresa CENIBRA - Celulose Nipo-Brasileira S.A. situados no município de Ipaba, Minas Gerais. As caracterizações geográficas e edafoclimáticas dos ambientes são apresentadas na Tabela 1. As progênies de irmãos completos utilizadas foram obtidas de cruzamentos controlados entre plantas de Eucalyptus urophylla e Eucalyptus grandis. Deve-se ressaltar que foram avaliadas 66 progênies comuns aos ambientes.

Os experimentos foram implantados no ano de 2001, no delineamento experimental de blocos casualizados com cinco repetições, parcelas constituídas de oito plantas e espaçamento de $3 \mathrm{x}$ $2 \mathrm{~m}$. Os tratos silviculturais utilizados foram os mesmos preconizados para os plantios comerciais da empresa.

No ano de 2004, aos três anos de idade, foram obtidas estimativas de incremento médio anual de madeira (IMA), em $\mathrm{m}^{3} / \mathrm{ha}$.ano. Por meio do NIR foram obtidos dados das características tecnológicas da madeira: densidade básica da madeira (DB), em $\mathrm{kg} / \mathrm{m}^{3}$, rendimento depurado de celulose (RD) e álcali efetivo ( $\mathrm{AE})$, ambas em porcentagem.

A avaliação estatística do teste de progênies foi feita por meio do procedimento de modelos mistos de Máxima Verossimilhança Restrita e Melhor Predição Linear não Viesada (Restricted Maximum Likelihood/Best Linear Unbiased Prediction - REML/BLUP). Nas análises não foram consideradas informações de pedigree. 
TABELA 1: Caracterizações geográficas e edafoclimáticas dos ambientes dos testes de progênies de eucaliptos em Ipaba - MG.

TABLE 1: Geographical and climate characterization of the environments of eucalypts progeny test in Ipaba, MG state.

\begin{tabular}{lccc}
\hline \multirow{2}{*}{ Características } & \multicolumn{3}{c}{ Ambientes } \\
\cline { 2 - 4 } & 7838000 & & 2 \\
\hline Latitude (UTM) & 7838450 & & 762500 \\
Longitude (UTM) & 260 & 300 \\
Altitude (m) & Baixada & & Encosta \\
Topografia & Aluvial & & Latossolo \\
Tipo de solo & & $1.229,80$ & \\
Precipitação (mm) & & 70,50 & \\
Umidade Relativa $(\%)$ & & 31,00 & \\
Temperatura máxima $\left({ }^{\circ} \mathrm{C}\right)$ & & 18,80 & \\
Temperatura mínima $\left({ }^{\circ} \mathrm{C}\right)$ & & 20,50 & \\
Temperatura média $\left({ }^{\circ} \mathrm{C}\right)$ & & & \\
\hline
\end{tabular}

Para tanto foi utilizado o programa computacional Seleção Genética Computadorizada - Selegen (RESENDE, 2007a). Na avaliação por ambiente foi utilizada rotina que considera progênies de irmãos completos, delineamento experimental de blocos completos, com várias plantas por parcela e uma única medição. As análises foram realizadas de acordo com o seguinte modelo estatístico:

$$
y=X_{r}+Z_{g}+W_{p}+e
$$

Em que: $y$ : vetor de dados; $r$ : vetor dos efeitos fixos de repetição somados à média geral; $g$ : vetor dos efeitos aleatórios genotípicos individuais $g \sim \mathrm{N}\left(0, \sigma_{\mathrm{g}}^{2}\right) ; p$ : vetor dos efeitos aleatórios de parcela $p \sim \mathrm{N}\left(0, \sigma_{\mathrm{p}}^{2}\right)$ e $e$ : vetor dos efeitos aleatórios dos erros ou resíduos $e \sim \mathrm{N}\left(0, \sigma_{\mathrm{e}}^{2}\right)$. As letras maiúsculas representam as matrizes de incidência para os referidos efeitos.

$\mathrm{Na}$ análise conjunta de ambientes foi utilizada rotina que considera progênies de irmãos completos, várias plantas por parcela, no delineamento de blocos completos, em vários ambientes e uma medição. O modelo estatístico utilizado foi (RESENDE, 2007a):

$$
y=X_{r}+Z_{g}+W_{p}+T_{i}+e
$$

Em que, $y$ : vetor de dados, $r$ : é o vetor dos efeitos fixos de repetição somados à média geral; $g$ : vetor dos efeitos aleatórios genotípicos individuais $g \sim \mathrm{N}\left(0, \sigma_{\mathrm{g}}^{2}\right) ; p$ : vetor dos efeitos aleatórios de parcela $p \sim \mathrm{N}\left(0, \sigma_{\mathrm{p}}^{2}\right) ; \mathrm{i}$ : vetor dos efeitos aleatórios da interaçao genótipos $\mathrm{x}$ ambientes $i \sim \mathrm{N} \quad\left(0, \sigma_{\mathrm{i}}^{2}\right)$ e $e$ : vetor dos efeitos aleatórios dos erros ou resíduos $e \sim \mathrm{N}\left(0, \sigma_{\mathrm{e}}^{2}\right)$. As letras maiúsculas representam as matrizes de incidência para os referidos efeitos.

A partir dessas análises foram obtidas as significâncias dos efeitos aleatórios dos modelos pelo teste da razão da verossimilhança (LRT) e análises de deviance para cada característica avaliada (RESENDE, 2007b). Além disso, foram obtidas as acurácias seletivas dos experimentos, as médias preditas, estimativas dos parâmetros genéticos das progênies para cada ambiente e na média de ambientes e as correlações genéticas do desempenho das progênies entre ambientes. A decomposição da interação em suas partes simples e complexa foi feita de acordo com a metodologia de Cruz e Castoldi (1991).

As correlações genéticas entre os desempenhos médios das progênies nos dois ambientes, para cada característica considerada, foram obtidas por meio do seguinte estimador (BERNARDO, 2002):

$$
r_{G x y}=\frac{C O V_{G_{x y}}}{\sqrt{\sigma_{G_{x}}^{2} \cdot \sigma_{G y}^{2}}}
$$

Em que, $\quad C O V_{G_{y y}}$ : covariância genética entre o desempenho das progênies nos ambientes 
$x$ e $y ; \sigma_{G_{x}}^{2}$ e $\sigma_{G_{y}}^{2}$ : variâncias genéticas entre as progênies nos ambientes $x$ e $y$, respectivamente.

No intuito de selecionar as melhores progênies, com base nas quatro características simultaneamente, foram empregados dois índices tradicionalmente utilizados no setor florestal: clássico e soma de postos. O índice clássico (SMITH, 1936; HAZEL, 1943) considera as covariâncias genéticas e fenotípicas entre os $n$ caracteres e também um peso econômico para cada caráter. $\mathrm{O}$ índice para cada progênie da população foi obtido pelo seguinte estimador (BERNARDO, 2010):

$$
I=b_{1} x_{1}+b_{2} x_{2}+\ldots+b_{n} x_{n}=\sum b_{i} x_{i}
$$

Em que, $I$ : índice calculado para cada progênie da população; $b_{i}$ : peso do caráter i e $x_{i}$ : valor fenotípico para o caráter $i$. Os valores de $b_{i}$ foram estimados por:

$$
b=P^{-1} G a
$$

Em que, $b$ : vetor $n \times 1$ dos valores de $b_{i} ; P^{-1}$ :matriz $n \times n$ das covariâncias fenotípicas entre caracteres; $G$ : matriz $n \times n$ das covariâncias genéticas entre caracteres e $a$ : vetor $n x 1$ dos pesos econômicos dos caracteres. Neste trabalho foram utilizados pesos econômicos iguais a um para os quatro caracteres.

O índice de soma de postos ou ranks foi proposto por Mulamba e Mock (1978) e consiste em classificar as progênies em relação a cada um dos caracteres, em ordem favorável ao melhoramento. Uma vez classificados, são somadas as ordens de cada genótipo referente a cada caráter, resultando uma medida adicional tomada como índice de seleção (CRUZ e REGAZZI, 1994). As análises, para ambos os índices, foram realizadas pelo programa computacional GENES (CRUZ, 2001).

Outro índice utilizado foi o somatório $\mathrm{Z}$ das variáveis padronizadas (MENDES et al., 2009). Pelo índice, os dados de caracteres de crescimento: IMA e tecnológicos da madeira: AE, DB e RD de todos os indivíduos do teste de progênies foram padronizados visando torná-los diretamente comparáveis. Assim, a variável $Z_{\mathrm{ij}}$ foi estimada pelo seguinte estimador (RAMALHO et al., 2012):

$$
Z_{i j}=\frac{x_{i j}-m_{. j}}{s_{. j}}
$$

Em que: $Z_{\mathrm{ij}}$ : valor da variável padronizada correspondente ao indivíduo $i$ na repetição $j$; $X_{i j}$ : média da característica considerada do indivíduo $i$ na repetição $j$; $m_{j}$ : média de todos os indivíduos na repetição $j$ e $S_{j}$ : desvio padrão fenotípico da média na repetição $j$. Como a variável $\mathrm{Z}$ pode assumir tanto valores negativos como positivos, foi adicionado uma constante de valor três, de modo a tornar os valores positivos. Nesse caso, a média populacional, em vez de zero, assumiu o valor três.

O emprego desse índice na seleção simultânea dos quatros caracteres, parte do pressuposto que quanto maior o valor de $\mathrm{Z}$ melhor. Contudo, deve ser salientado que para a característica $\mathrm{AE}$, quanto menor o seu valor, mais econômico é o processo de extração de celulose. Assim, para tornar os quatro caracteres atuantes na mesma direção, foi necessário inverter os valores do caráter $\mathrm{AE}$, antes de sua padronização para assim facilitar a visualização gráfica. Para o índice somatório $\mathrm{Z}$ das variáveis padronizadas, foram também utilizados pesos econômicos iguais a um para todos os caracteres considerados.

Após padronização das variáveis, foi obtido o somatório de $\mathrm{Z}$ para cada indivíduo, o qual foi submetido a uma análise de deviance e em seguida, obtidas médias preditas das progênies para o somatório $\mathrm{Z}$, sendo as mesmas ranqueadas em sentido favorável ao melhoramento. Foram também estimados os parâmetros genéticos para o índice. Adicionalmente, foi utilizado o método gráfico que permite uma rápida e fácil identificação das progênies de melhor desempenho.

Posteriormente, foram realizadas comparações entre os três índices considerados e obtida a porcentagem de coincidências entre as $20 \%$ melhores progênies obtidas para cada índice.

\section{RESULTADOS E DISCUSSÃO}

Os dois ambientes em que foram conduzidos os experimentos, embora fossem localizados no mesmo município, apresentam diferenças marcantes com relação ao relevo. Um experimento foi instalado em ambiente tipicamente de baixada e o outro de encosta. Além do que, eles também diferem nas propriedades do solo (Tabela 1). Essas diferenças contribuíram para que fossem detectadas diferenças significativas $(\mathrm{P} \leq 0,01)$ entre os caracteres $\mathrm{AE}$ e $\mathrm{DB}$, nos dois ambientes (Tabelas 2, 3 e 4). De modo geral, o desempenho médio das progênies do ambiente 2, ou seja, situado em região de encosta, foi superior 
TABELA 2: Análises de deviances para os caracteres incremento médio anual de madeira (IMA), densidade básica (DB), álcali efetivo (AE) e rendimento depurado de celulose (RD) obtidos em teste de progênies de eucalipto em Ipaba - MG, Ambiente 1.

TABLE 2: Analysis of deviances for the character mean annual increment of wood (IMA), basic density (BD), effective alkali (EA) and screened yield pulp (RD) obtained in eucalyptus progeny test in Ipaba, MG state, environment 1.

\begin{tabular}{|c|c|c|c|c|c|c|c|c|}
\hline \multirow{3}{*}{ Efeito } & \multicolumn{8}{|c|}{ Ambiente 1} \\
\hline & \multicolumn{2}{|c|}{ IMA (m³/ha.ano) } & \multicolumn{2}{|c|}{$\mathrm{DB}\left(\mathrm{kg} / \mathrm{m}^{3}\right)$} & \multicolumn{2}{|c|}{$\mathrm{AE}^{++}(\%)$} & \multicolumn{2}{|c|}{$\mathrm{RD}(\%)$} \\
\hline & Deviance & LRT $^{1}$ & Deviance & LRT $^{1}$ & Deviance & LRT $^{1}$ & Deviance & LRT $^{1}$ \\
\hline Progênies ${ }^{+}$ & $17.540,39$ & $116,93 * *$ & $16.897,94$ & $122,11 * *$ & $9.998,63$ & $129,14 * *$ & $3.442,85$ & $91,79 * *$ \\
\hline Parcela $^{+}$ & $17.425,31$ & $1,85^{\mathrm{NS}}$ & $16.843,76$ & $67,93 * *$ & $9.899,88$ & $30,49 * *$ & $3.427,09$ & $76,03 * *$ \\
\hline Modelo Completo & $17.423,46$ & - & $16.775,83$ & - & $9.869,49$ & - & $3.351,06$ & - \\
\hline Acurácia & \multicolumn{2}{|c|}{93,27} & \multicolumn{2}{|c|}{93,55} & \multicolumn{2}{|c|}{93,62} & \multicolumn{2}{|c|}{91,22} \\
\hline Média & \multicolumn{2}{|c|}{54,83} & \multicolumn{2}{|c|}{354,30} & \multicolumn{2}{|c|}{69,40} & \multicolumn{2}{|c|}{50,37} \\
\hline
\end{tabular}

Em que: ${ }^{1}$ Teste da razão da verossimilhança, com distribuição com 1 grau de liberdade; ${ }^{* *}$ Significativo a $1 \%$ de probabilidade pelo teste de $X^{2}(1 \%=6,63 ; 5 \%=3,84) ; \mathrm{NS}=$ não significativo; ${ }^{+}$Deviance do modelo ajustado sem os referidos efeitos $\mathrm{e}^{++}$Valores invertidos.

TABELA 3: Análises de deviances para os caracteres incremento médio anual de madeira (IMA), densidade básica (DB), álcali efetivo (AE) e rendimento depurado de celulose (RD) obtidos em teste de progênies de eucalipto em Ipaba - MG, Ambiente 2.

TABLE 3: Analysis of deviances for the character mean annual increment of wood (IMA), basic density (BD), effective alkali (EA) and screened yield pulp (RD) obtained in eucalyptus progeny test in Ipaba, MG state, environment 2.

\begin{tabular}{|c|c|c|c|c|c|c|c|c|}
\hline \multirow{3}{*}{ Efeito } & \multicolumn{8}{|c|}{ Ambiente 2} \\
\hline & \multicolumn{2}{|c|}{$\operatorname{IMA}\left(\mathrm{m}^{3} /\right.$ ha.ano $)$} & \multicolumn{2}{|c|}{$\mathrm{DB}\left(\mathrm{kg} / \mathrm{m}^{3}\right)$} & \multicolumn{2}{|c|}{$\mathrm{AE}^{++}(\%)$} & \multicolumn{2}{|c|}{$\mathrm{RD}(\%)$} \\
\hline & Deviance & $\mathrm{LRT}^{1}$ & Deviance & LRT $^{1}$ & Deviance & LRT $^{1}$ & Deviance & LRT $^{1}$ \\
\hline Progênies $^{+}$ & $18.100,22$ & $150,53^{* *}$ & $17.822,58$ & $34,68^{* *}$ & $10.690,01$ & $190,11^{* *}$ & $3.856,59$ & $125,63^{* *}$ \\
\hline Parcela $^{+}$ & 17.949 .81 & $0,12^{\mathrm{NS}}$ & 17.917 .47 & $129,57^{* *}$ & 10.510 .02 & $10,12^{* *}$ & 3.756 .42 & $25,46^{* *}$ \\
\hline Modelo Completo & $17.949,69$ & - & $17.787,90$ & - & $10.499,90$ & - & $3.730,96$ & - \\
\hline Acurácia & \multicolumn{2}{|c|}{93,87} & \multicolumn{2}{|c|}{81,85} & \multicolumn{2}{|c|}{95,85} & \multicolumn{2}{|c|}{93,52} \\
\hline Média & \multicolumn{2}{|c|}{58,73} & \multicolumn{2}{|c|}{389,06} & \multicolumn{2}{|c|}{73,46} & \multicolumn{2}{|c|}{50,89} \\
\hline
\end{tabular}

Em que: ${ }^{1}$ Teste da razão da verossimilhança, com distribuição com 1 grau de liberdade; ${ }^{* *}$ Significativo a $1 \%$ de probabilidade pelo teste de $\chi^{2}(1 \%=6,63) ; \mathrm{NS}=$ não significativo; ${ }^{+}$Deviance do modelo ajustado sem os referidos efeitos $\mathrm{e}^{++}$Valores invertidos.

ao ambiente 1 , de baixada (Tabelas 2 e 3). Para os quatro caracteres, em média, o desempenho do ambiente 2 foi $5,77 \%$, superior ao do ambiente 1 .

Um aspecto importante em experimentos dessa natureza é a precisão experimental com que as progênies foram avaliadas. Verifica-se pela acurácia que a precisão foi de alta a muito alta para todos os caracteres (Tabelas 2, 3 e 4) (RESENDE 2007b), condição essa muito favorável para a seleção.

Foram encontradas diferenças significativas $(P \leq 0,01)$ entre progênies para todas as características analisadas, tanto nas análises por ambiente quanto nas conjuntas (Tabelas 2, 3 e 4). A presença de variabilidade entre as progênies pode também ser constatada por meio das distribuições de frequências das características na média dos ambientes (Figura 1). Verifica-se que para a característica IMA, as estimativas variaram de 23,46 a 100,62 e em torno de $48 \%$ das progênies apresentaram desempenho superior à média geral. Essa mesma porcentagem foi encontrada para as características AE, com variação de 63,29 e 80,12 
TABELA4: Análises de deviances para os caracteres incremento médio anual de madeira (IMA), densidade básica (DB), álcali efetivo (AE) e rendimento depurado de celulose (RD) obtidos em teste de progênies de eucalipto em Ipaba - MG, dados na média de ambientes.

TABLE 4: Analysis of deviances for the characters mean annual increment of wood (IMA), basic density (BD), effective alkali (EA) and screened yield pulp (RD) obtained in eucalyptus progeny test in Ipaba, MG state, data on average environments.

\begin{tabular}{|c|c|c|c|c|c|c|c|c|}
\hline \multirow{3}{*}{ Efeito } & \multicolumn{8}{|c|}{ Conjuntas de ambientes } \\
\hline & \multicolumn{2}{|c|}{ IMA (m³/ha.ano) } & \multicolumn{2}{|c|}{$\mathrm{DB}\left(\mathrm{kg} / \mathrm{m}^{3}\right)$} & \multicolumn{2}{|c|}{$\mathrm{AE}^{++}(\%)$} & \multicolumn{2}{|c|}{$\mathrm{RD}(\%)$} \\
\hline & Deviance & LRT $^{1}$ & Deviance & LRT $^{1}$ & Deviance & LRT $^{1}$ & Deviance & LRT $^{1}$ \\
\hline Progênies $^{+}$ & $35.377,15$ & $81,48^{* *}$ & $34.575,46$ & $22,57^{* *}$ & $20.373,93$ & $63,29^{* *}$ & $7.091,44$ & $59,12^{* *}$ \\
\hline Parcela $^{+}$ & $35.296,34$ & $0,67^{\mathrm{NS}}$ & $34.750,35$ & $197,46^{* *}$ & $20.349,04$ & $38,40^{* *}$ & $7.127,57$ & $95,25^{* *}$ \\
\hline Progênies x Ambientes & $35.296,04$ & $0,37^{\mathrm{NS}}$ & $34.571,68$ & $18,79^{* *}$ & $20.323,01$ & $12,37^{* *}$ & $7.035,84$ & $3,52^{\mathrm{NS}}$ \\
\hline Modelo Completo & $35.295,67$ & - & $34.552,89$ & - & $20.310,64$ & - & $7.032,32$ & - \\
\hline Acurácia & \multicolumn{2}{|c|}{94,99} & \multicolumn{2}{|c|}{94,99} & \multicolumn{2}{|c|}{93,11} & \multicolumn{2}{|c|}{92,56} \\
\hline Média & \multicolumn{2}{|c|}{56,73} & \multicolumn{2}{|c|}{371,77} & \multicolumn{2}{|c|}{71,52} & \multicolumn{2}{|c|}{50,63} \\
\hline
\end{tabular}

Em que: ${ }^{1}$ Teste da razão da verossimilhança, com distribuição com 1 grau de liberdade; ${ }^{* *}$ Significativo a $1 \%$ de probabilidade pelo teste de $\chi^{2}(1 \%=6,63)$; NS $=$ não significativo; ${ }^{+}$Deviance do modelo ajustado sem os referidos efeitos $\mathrm{e}^{++}$Valores invertidos.
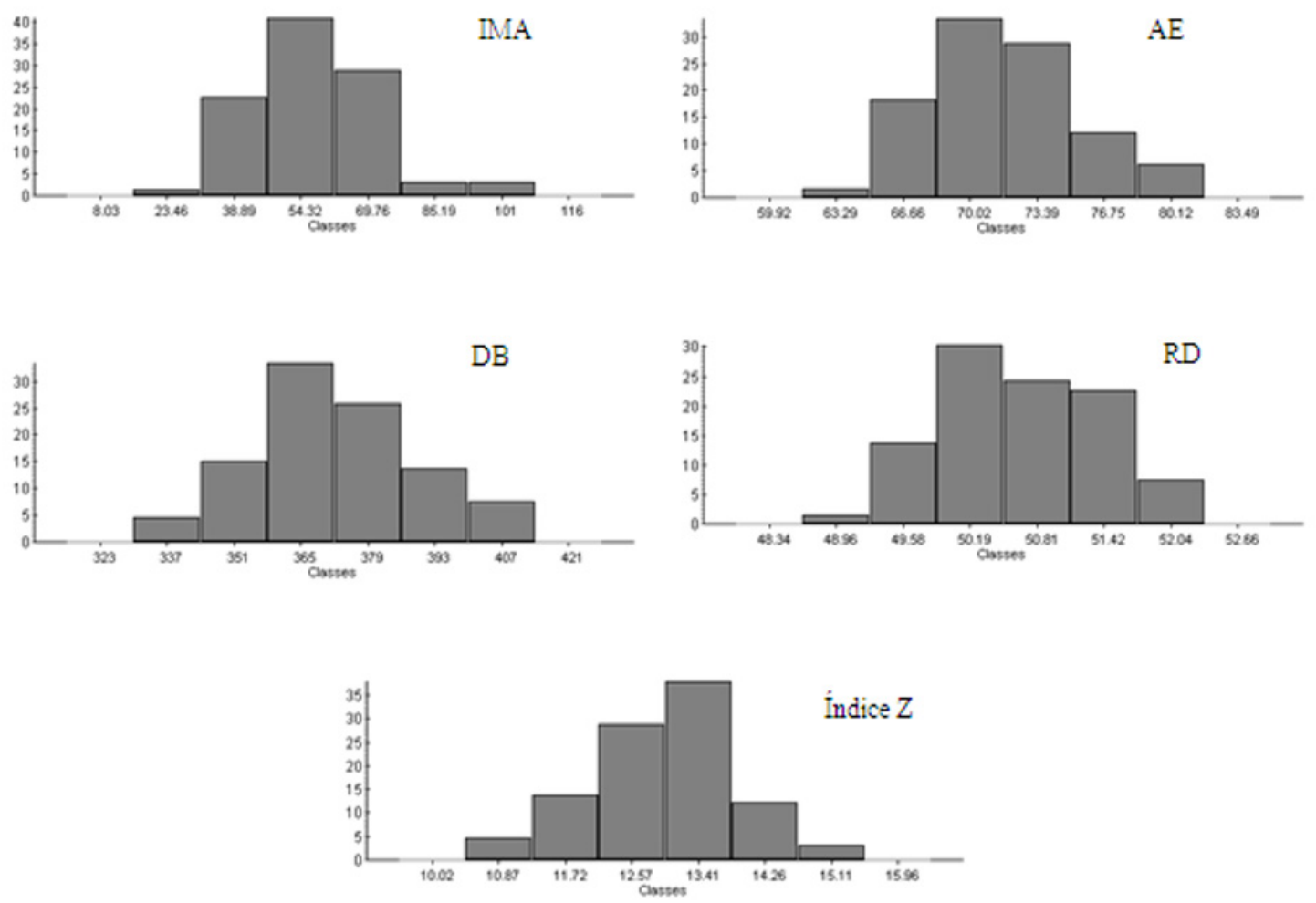

FIGURA 1: Distribuição de frequências dos caracteres incremento médio anual (IMA), em m³/ha/ano; álcali efetivo (AE), em porcentagem; densidade básica (DB), em $\mathrm{kg} / \mathrm{m}^{3}$; rendimento depurado em celulose (RD), em porcentagem e do índice $\mathrm{Z}$ obtidos na avaliação de progênies de Eucalyptus spp, dados da análise conjunta de ambientes.

FIGURE 1: Distribution of frequencies of the trait mean annual increment (IMA) in $\mathrm{m}^{3} / \mathrm{ha} / \mathrm{year}$; effective alkali (AE), in percentage, basic density (BD), in $\mathrm{kg} / \mathrm{m}^{3}$; screened yield of cellulose (RD), in percentage and $Z$ index at eucalyptus progeny test, data from the joint analysis of environments. 
e RD, 48,96 e 52,04. Para DB, as estimativas variaram de 337,10 a 407,12, com aproximadamente $45 \%$ das progênies com comportamento superior à média geral.

A interação progênies $\mathrm{x}$ ambientes foi significativa para o caráter AE (Tabela 4). No entanto, a estimativa da variância da interação progênies x locais foi de baixa magnitude $(1,60)$, correspondendo a apenas $12,25 \%$ da variância genética entre progênies $(13,05)$. Na decomposição da interação (CRUZ e CASTOLDI, 1991) foi constatado que houve predominância da parte simples, correspondendo a $72,45 \%$. Vale ainda ressaltar que a correlação genética entre os desempenhos médios das progênies nos dois ambientes foi alta, $r_{G_{A E}}=0,90$. Do exposto, podese inferir que não houve alteração expressiva na classificação das progênies entre os ambientes. Para a característica $\mathrm{AE}$, não foram encontrados trabalhos focando a interação progênies $\mathrm{x}$ ambientes.

Para a característica DB, foi também observada interação progênies $\mathrm{x}$ ambientes significativa (Tabela 4), sendo que a relação entre a variância da interação progênies $\mathrm{x}$ ambientes $(94,05)$ e a variância genética $(209,22)$ entre as progênies foi de $45 \%$. É importante salientar que a parte simples da interação correspondeu a $66,40 \%$. Foi constatado que a estimativa da correlação genética entre o desempenho das progênies nos dois ambientes foi elevada, $r_{G_{D B}}=0,75$. A partir desses resultados, infere-se que não ocorreu mudança expressiva na classificação das progênies nos ambientes avaliados para a característica DB. Na literatura existem relatos da ocorrência de interação progênies $\mathrm{x}$ ambientes para essa característica, em que foram obtidas altas estimativas de correlações entre o desempenho médio das progênies nos vários locais (MUNERI e RAYMOND, 2000; KUBE et al., 2001; COSTA e SILVA et al., 2009). Em outros trabalhos, essa interação não foi significativa (POKE et al., 2006; LIMA et al., 2011).

Para os caracteres IMA e RD, a interação progênies $\mathrm{x}$ ambientes foi não significativa $(\mathrm{P} \leq 0,01)$ (Tabela 4). Assim, pode-se inferir que o comportamento das progênies foi coincidente nos dois ambientes avaliados. Esses resultados podem ser corroborados pelas altas estimativas de correlações genéticas entre os desempenhos das progênies nos dois ambientes, $r_{G_{I K A}}=0,99$ e $r_{G_{R D}}=0,93$. Não foram encontrados estudos abordando interação progênies $\mathrm{x}$ ambientes para
IMA no Brasil. No entanto, para outros caracteres de crescimento no gênero Eucalyptus no Brasil, tem sido observado que as interações progênies $\mathrm{x}$ ambientes são de pequena magnitude e com predominância da parte simples (MORI et al., 1988; SANTOS et al., 1990; PEREIRA et al., 1997; LIMA et al., 2011; REIS et al., 2011). No melhoramento visando à produção de polpa celulósica, progênies de meios irmãos de Eucalyptus nitens foram avaliadas em três locais na Tasmânia, Austrália. Foi constatado que para conteúdo de celulose, caráter utilizado como indicador do rendimento em polpa, a interação progênies $x$ ambientes foi de pequena magnitude. Corroborando esse resultado, as estimativas das correlações entre os desempenhos das progênies entre os ambientes variaram de 0,69 a 0,98 , sendo consideradas de alta magnitude (KUBE et al., 2001).

Na Tabela 5 são apresentadas as $20 \%$ melhores progênies, ou seja, as 14, que foram selecionadas na média dos dois ambientes para todos os índices de seleção utilizados. Observa-se que a correspondência entre as progênies selecionadas por meio dos diferentes índices foi boa. Constata-se que pelo menos $57 \%$ das progênies foram comuns aos três índices.

É importante mencionar que o somatório $\mathrm{Z}$ das variáveis padronizadas pode ser estimado por repetição e assim, é possível realizar uma análise de deviance. Neste contexto, constatou-se que as progênies diferiram com relação ao índice $Z$ $(\mathrm{P} \leq 0,01)$, para cada ambiente e na conjunta (Tabela 5). A presença de variabilidade entre as progênies, quando se consideram os quatro caracteres simultaneamente, pode também ser comprovada por meio das distribuições de frequências dos valores do índice Z (Figura 1). As estimativas da herdabilidade do somatório de $Z$, na média de progênies, foram relativamente altas, $60 \%$ no Ambiente 1 e $51 \%$ no Ambiente 2. Quando se considerou a herdabilidade para a seleção na média de progênies dos dois ambientes, a estimativa foi também relativamente alta, $\mathrm{h}^{2}=57 \%$, ou seja, boa parte da variância fenotípica é devido a causas genéticas.

Outra vantagem do índice $Z$ é que, adicionalmente, ele permite verificar, por meio de uma análise gráfica, em quais caracteres envolvidos a progênie tem alguma deficiência. Assim, pôde-se observar que as progênies 58, no Ambiente 1 e 59, no Ambiente 2, apresentaram valores de $\mathrm{Z}$ acima da média da população para as quatro características consideradas (Figura 2). Deve-se ressaltar que os 
TABELA 5: Progênies selecionadas de acordo com os índices somatório $Z$ das variáveis padronizadas, clássico e soma de postos obtidos na avaliação de progênies de eucalipto, dados da conjunta de ambientes.

TABLE 5: Progenies selected according to the sum of standardized variables, classic and sum of rank indexes in eucalyptus progeny test, data from the joint environments.

\begin{tabular}{cccc}
\hline \multirow{2}{*}{ Classificação da Progênie } & \multicolumn{3}{c}{ Índices } \\
\cline { 2 - 4 } & Somatório $Z$ & Clássico & Soma de Postos \\
\hline 1 & 58 & 58 & 59 \\
3 & 59 & 59 & 21 \\
4 & 21 & 64 & 8 \\
5 & 6 & 12 & 42 \\
6 & 42 & 21 & 43 \\
7 & 7 & 43 & 54 \\
8 & 8 & 42 & 36 \\
9 & 55 & 20 & 46 \\
10 & 43 & 8 & 58 \\
11 & 57 & 6 & 47 \\
12 & 5 & 7 & 57 \\
13 & 15 & 16 & 64 \\
14 & 64 & 4 & 6 \\
\hline
\end{tabular}

TABELA 6: Análises de deviances para o índice Z obtido em testes de progênies de eucalipto em Ipaba MG, dados por ambientes e da conjunta de ambientes.

TABLE 6: Analysis of deviances to $\mathrm{Z}$ index obtained at eucalyptus progeny test in Ipaba, MG state, data environments and joint environments.

\begin{tabular}{ccccccc}
\hline \multirow{2}{*}{ Efeitos } & \multicolumn{9}{c}{ Índice Z } \\
\cline { 2 - 7 } & \multicolumn{2}{c}{ Ambiente 1 } & \multicolumn{2}{c}{ Ambiente 2 } & \multicolumn{2}{c}{ Conjunta } \\
\cline { 2 - 7 } & Deviance & LRT $^{1}$ & Deviance & LRT $^{1}$ & Deviance & LRT $^{1}$ \\
\hline Progênies $^{+}$ & $6.825,62$ & $23,59^{* *}$ & $6.983,42$ & $13,52^{* *}$ & $13.788,17$ & $10,82^{* *}$ \\
Parcela $^{+}$ & $7.002,23$ & $200,2^{* *}$ & $7.046,10$ & $76,20^{* *}$ & $14.048,11$ & $270,76^{* *}$ \\
Progênies x Locais & - & - & - & - & $13.781,41$ & $4,06^{*}$ \\
Modelo Completo & $6.802,03$ & - & $6.969,90$ & - & $13.777,35$ & - \\
Acurácia & 77,70 & & 71,39 & & 74,34 \\
Média & 12,99 & & 12,96 & \multicolumn{2}{c}{12,98} \\
\hline
\end{tabular}

Em que: ${ }^{1}$ Teste da razão da verossimilhança, com distribuição com 1 grau de liberdade; ${ }^{*}$ Significativo a 5\% de probabilidade pelo teste de $\chi^{2}(5 \%=3,84) ;{ }^{* *}$ Significativo a $1 \%$ de probabilidade pelo teste de $\chi^{2}(1 \%=6,63)$ e ${ }^{+}$Deviance do modelo ajustado sem os referidos efeitos.

desempenhos dessas duas progênies demonstram a existência de ganhos com a seleção. Entretanto, foi observado que as progênies 63 e 39 apresentaram os menores valores do índice $\mathrm{Z}$, nos Ambientes 1 e 2, respectivamente. Isso se deve ao desempenho inferior dessas progênies para a característica IMA de madeira, uma vez que para os caracteres $\mathrm{AE}, \mathrm{DB}$ e $\mathrm{RD}$, os desempenhos foram superiores à média da população.

Assim, a facilidade de obtenção do índice $\mathrm{Z}$, aliada à possibilidade de ser submetido à análise estatística e à análise gráfica do desempenho de cada progênie sugere que esse índice é uma boa opção para os melhoristas de Eucalyptus, como também já 

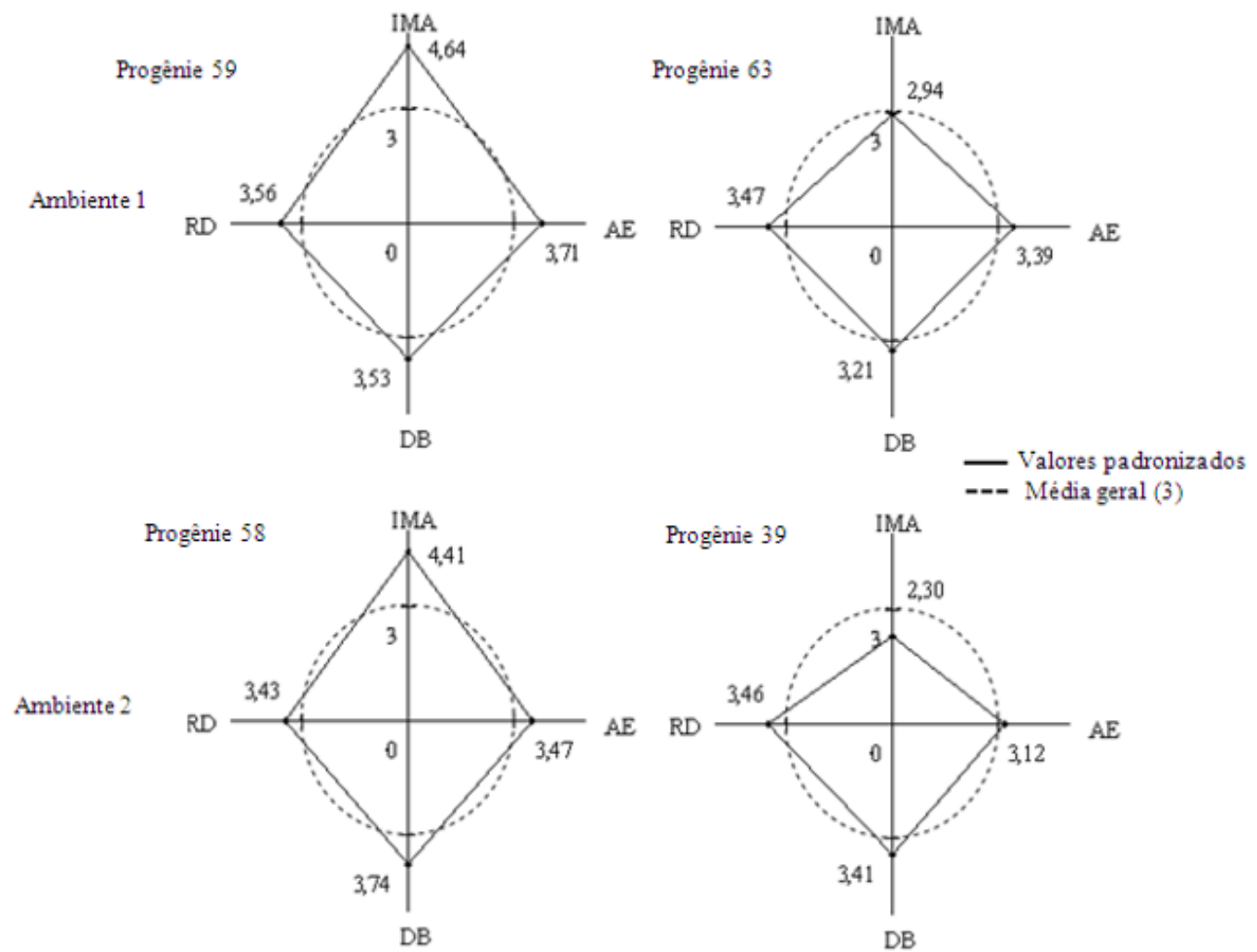

FIGURA 2: Representação gráfica dos valores padronizados dos caracteres incremento médio anual (IMA), álcali efetivo (AE), densidade básica (DB) e rendimento depurado em celulose (RD) das progênies de eucalipto que apresentaram os mais altos e mais baixos valores de $\mathrm{Z}$ em cada um dos ambientes.

FIGURE 2: Graphical representation of the standardized values of the trait mean annual increment (IMA), effective alkali (AE), basic density (DB) and screened yield of cellulose (RD) of the eucalyptus progeny test showed that the highest and lowest values of $Z$ in each environment.

constatado em feijão (MENDES et al., 2009).

Um dos focos desse trabalho é verificar o possível efeito da interação progênies $\mathrm{x}$ ambientes no desempenho ao se considerar vários caracteres simultaneamente. Observou-se que para o índice Z, a interação progênies $x$ ambientes foi significativa $(P \leq 0,05)$ (Tabela 6). A relação entre as estimativas da variância da interação progênies $\mathrm{x}$ ambientes $(0,19)$ e variância genética entre progênies $(0,45)$ foi expressiva, $42,20 \%$. A partir do desdobramento da interação, pela metodologia de Cruz e Castoldi (1991), foi constatado que houve predominância da parte simples da interação $(72,45 \%)$. Além do que a estimativa da correlação genética entre as médias de $\mathrm{Z}$ das progênies, nos dois ambientes, foi alta, 0,77. Deste modo, infere-se que não houve mudança marcante no ranqueamento das progênies na seleção simultânea de caracteres, nos dois ambientes considerados.

\section{CONCLUSÕES}

Houve boa concordância na seleção de progênies pelos índices: clássico, soma de postos e somatório $\mathrm{Z}$ das variáveis padronizadas. Assim, este último também consiste em boa opção a ser utilizada no setor florestal.

$\mathrm{O}$ emprego do índice somatório $\mathrm{Z}$ das variáveis padronizadas parte do pressuposto que quanto maior o valor de Z, melhor. Oportunamente, diferentes pesos econômicos podem ser utilizados para cada um dos caracteres considerados. Além do mais, o método gráfico permite visualizar o desempenho do genótipo para o conjunto de caracteres.

O método gráfico, aliado ao índice somatório das variáveis padronizadas, permite melhor visualização do desempenho do genótipo quando avaliado sob diferentes caracteres. 
$\mathrm{O}$ índice somatório $\mathrm{Z}$ das variáveis padronizadas mostrou-se eficiente no estudo da interação genótipos $\mathrm{x}$ ambientes.

\section{AGRADECIMENTOS}

Os autores agradecem à Empresa CENIBRA - Celulose Nipo-Brasileira S.A. pela cessão dos dados utilizados neste trabalho e ao $\mathrm{CNPq}$ pela bolsa concedida aos autores.

\section{REFERÊNCIAS BIBLIOGRÁFICAS}

ASSIS T. F., MAFIA R. G. 2007. Hibridação e clonagem. In: BORÉM, A. (ed). Biotecnologia Florestal. Viçosa: UFV, 2007. p. 93-121.

BERNARDO, R. Breeding for quantitative traits in plants. Woodbury, Minnesota: Stemma Press, 2002. $368 \mathrm{p}$.

COSTA E SILVA, J. et al. Genetic parameters for growth, wood density and pulp yield in Eucalyptus globulus. Tree Genetics \& Genomes, Berlin, v. 5, p. 291-305, May. 2009.

CRUZ, C. D.; CASTOLDI, F. Decomposição $\mathrm{da}$ interação genótipos $\mathrm{x}$ ambientes em partes simples e complexa. Revista Ceres, Viçosa, v. 38, p. 422-430, ago. 1991.

CRUZ, C. D. PROGRAMA GENES: versão Windows: aplicativo computacional em genética e estatística. Viçosa: UFV, 2001. 648 p.

CRUZ, C. D.; CARNEIRO, P. C. S. Modelos Biométricos Aplicados ao Melhoramento Genético. Viçosa: UFV, 2006. v. 2.585 p.

CRUZ, C. D.; REGAZZI,A. J. Modelos Biométricos Aplicados ao Melhoramento Genético. Viçosa: UFV, 1994. 390 p.

HAZEL, L. N. The genetic basics for constructing selections indexes. Genetics, New York, v. 28, n. 6, p. 476-490, 1943.

KUBE, P. D. et al. Genetic parameters for diameter, basic density, cellulose content and fibre properties for Eucalyptus nitens. Forest Genetics, Zvolen, v. 8, n. 4, p. 285-294, Sept./Dec. 2001.

LIMA, J. L. et al.. Early selection of parents and trees Eucalyptus full-sib progeny tests. Crop Breeding and Applied Biotechnology, Campos dos Goytacazes, n. 11, p. 10-16, 2011.

MARTINS, I. S. et al. Alternativas de índices em uma população de Eucalyptus grandis Hill ex Maiden. Cerne, Lavras, v. 12, n. 3, p. 287-291, jul./set. 2006.

MARTINS, I. S. et al. Eficiência da seleção univariada direta e indireta e de índices de seleção em Eucalyptus grandis. Revista Árvore, Viçosa, v. 27, n. 3, p. 327-333, maio/ jun. 2003.

MENDES, F. F. et al. Índice de seleção para escolha de populações segregantes do feijoeiro-comum. Pesquisa Agropecuária Brasileira, Brasília, v. 44, p. 1312-1318, out. 2009.

MORI, E. S. et al. Variação genética e interação progênies x locais em Eucalyptus urophylla. IPEF, Piracicaba, n. 39, p. 53-63, ago. 1988.

MULAMBA. N. N.; MOCK, J. J. Improvement of yield potential of the Eto Blanco maize (Zea mays L.) population by breeding for plant traits. Egypt Journal Genetic Cytology, Alexandria, v. 7, p. 40-51, May. 1978.

MUNERI,A.; RAYMOND,C.A. Genetic parameters and genotype-by-environment interactions for basic density, pilodyn penetration and stem diameter in Eucalyptus globulus. Forest Genetics, Vienna, v. 7, n. 4, p. 317-328, Oct. 2000.

NUNES, G. H. S. et al. Implicações da interação genótipos $\mathrm{x}$ ambientes na seleção de clones de eucalipto. Cerne, Lavras, v. 8, n. 1, p. 49-58, jan./jul. 2002.

PASQUINI, C. Near Infrared Spectroscopy: Fundamentals, Practical Aspects and Analytical Applications. Journal Brazilian Chemistry Society, Campinas, v. 14, n. 2, p. 198-219, 2003.

PAULA, R. C. de. et al. Predição de ganhos genéticos em melhoramento florestal. Pesquisa Agropecuária Brasileira, Brasília, v. 37, n. 2, p. 159-165, fev. 2002.

PEREIRA, A. B. et al. Eficiência da seleção precoce em famílias de meios-irmãos de Eucalyptus camaldulensis Dehnh., na região noroeste do Estado de Minas Gerais. Cerne, Lavras, v. 3, n. 1, jul. 1997. POKE, F. S.; RAYMOND, C. A. Predicting Extractives, Lignin, and Cellulose Contents Using Near Infrared Spectroscopy on Solid Wood in Eucalyptus globulus. Journal of Wood Chemistry and Technology, v. 26, n. 2, p.187 - 199, 2006.

RAMALHO, M. A. P. et al. Experimentação em genética e melhoramento de plantas. Lavras: UFLA, 2005. $300 \mathrm{p}$.

REIS, C. A. F. et al. Correspondence between performance of Eucalyptus spp trees selected from family and clonal tests. Genetics and Molecular Research, v. 10, n. 2, p. 1172-1179, 2011. RESENDE, M. D. V. Software Selegen - REML/ BLUP: sistema estatístico e seleção genética computadorizada via modelos mistos. Colombo: Embrapa Florestas, 2007a. 359 p. 
RESENDE, M. D. V. Matemática e estatística na análise de experimentos e no melhoramento genético. Colombo: Embrapa Florestas, 2007b. $561 \mathrm{p}$.

SANTOS, P. E. T. et al. Potencial para programas de melhoramento, estimativas de parâmetros genéticos e interação progênies x locais em populações de Eucalyptus urophylla. IPEF, Piracicaba, n. 43/44, p. 11-19, jan./dez. 1990. SILVA, P.H.M.; L. E. G. BARRICHELO.Progressos recentes na área florestal. In: PATERNIANI, E.
(Ed.). Ciência, Agricultura e Sociedade. Brasília: Embrapa, p. 439-456. 2006.

SMITH, H. F. A discriminant function for plant selection. Annual Eugenics. Cambridge, v. 7, p. 240-250, 1936.

VENCOVSKY, R.; RAMALHO, M. A. P. Contribuições do melhoramento genético de plantas no Brasil. In: PATERNIANI, E. (ed.). Agricultura brasileira e pesquisa agropecuária. Brasília: Embrapa, 2000. p. 57-89. 